\title{
Detection of cancer through exhaled breath: a systematic review
}

\author{
Agne Krilaviciute ${ }^{1}$, Jonathan Alexander Heiss ${ }^{1}$, Marcis Leja², Juozas Kupcinskas ${ }^{3}$, \\ Hossam Haick ${ }^{4}$ and Hermann Brenner ${ }^{1,5,6}$ \\ ${ }^{1}$ Division of Clinical Epidemiology and Aging Research, German Cancer Research Center (DKFZ), Heidelberg, Germany \\ ${ }^{2}$ Faculty of Medicine, University of Latvia, Digestive Diseases Center GASTRO, and Riga East University Hospital, Riga, Latvia \\ ${ }^{3}$ Department of Gastroenterology, Lithuanian University of Health Sciences, Kaunas, Lithuania \\ ${ }^{4}$ Department of Chemical Engineering and Russell Berrie Nanotechnology Institute, Technion - Israel Institute of Technology, \\ Haifa, Israel \\ ${ }^{5}$ Division of Preventive Oncology, German Cancer Research Center (DKFZ), Heidelberg, Germany \\ ${ }^{6}$ German Cancer Consortium (DKTK), German Cancer Research Center (DKFZ), Heidelberg, Germany \\ Correspondence to: Hossam Haick, email: hhossam@technion.ac.il \\ Keywords: breath analysis, cancer detection, volatile organic compound, VOC, systematic review
}

Received: August 03, $2015 \quad$ Accepted: September 01, $2015 \quad$ Published: September 30, 2015

This is an open-access article distributed under the terms of the Creative Commons Attribution License, which permits unrestricted use, distribution, and reproduction in any medium, provided the original author and source are credited.

\section{ABSTRACT}

Background: Timely diagnosis of cancer represents a challenging task; in particular, there is a need for reliable non-invasive screening tools that could achieve high levels of adherence at virtually no risk in population-based screening. In this review, we summarize the current evidence of exhaled breath analysis for cancer detection using standard analysis techniques and electronic nose.

Methods: Relevant studies were identified searching Pubmed and Web of Science databases until April 30, 2015. Information on breath test performance, such as sensitivity and specificity, was extracted together with volatile compounds that were used to discriminate cancer patients from controls. Performance of different breath analysis techniques is provided for various cancers together with information on methodological issues, such as breath sampling protocol and validation of the results.

Results: Overall, 73 studies were included, where two-thirds of the studies were conducted on lung cancer. Good discrimination usually required a combination of multiple biomarkers, and area under the receiver operating characteristic curve or accuracy reached levels of 0.9 or higher in multiple studies. In $25 \%$ of the reported studies, classification models were built and validated on the same datasets. Huge variability was seen in different aspects among the studies.

Conclusions: Analyses of exhaled breath yielded promising results, although standardization of breath collection, sample storage and data handling remain critical issues. In order to foster breath analysis implementation into practice, larger studies should be implemented in true screening settings, paying particular attention to standardization in breath collection, consideration of covariates, and validation in independent population samples.

\section{INTRODUCTION}

Cancer is a leading cause of death worldwide [1]. In 2012, cancer accounted for 8.2 million deaths, and number of deaths is projected to increase to over 13 million in 2030 [2]. Early detection is essential to improve successful treatment and reduce cancer mortality and cancer screening in the asymptomatic general population might be a particularly promising approach to achieve this goal. However, only few cancer screening programs are widely used. For most deadly cancers, such as pancreatic or gastric cancer, no reliable population-based screening exists, and for other common malignancies, like breast or colorectal cancer, there is large potential for improving currently used screening methods. In particular, there is 
a need for reliable non-invasive screening tools that could achieve high levels of adherence at virtually no risk in population-based screening.

Breath tests might be a particularly promising approach for non-invasive cancer screening. The analysis of volatile organic compounds (VOCs) in exhaled breath can provide information on metabolic processes in the body which are modified by underlying diseases [35], though a detailed picture of VOCs origin is still not complete.

In this systematic review, we summarize the current evidence of exhaled breath analysis for cancer detection. Performance of different breath analysis techniques is provided for various cancers together with information on methodological issues, such as breath sampling protocol, validation of the results, and VOCs proposed as cancerrelated compounds.

\section{RESULTS}

\section{Literature search}

Figure 1 shows the process of study selection. In total, 1277 papers were identified of which 262 were

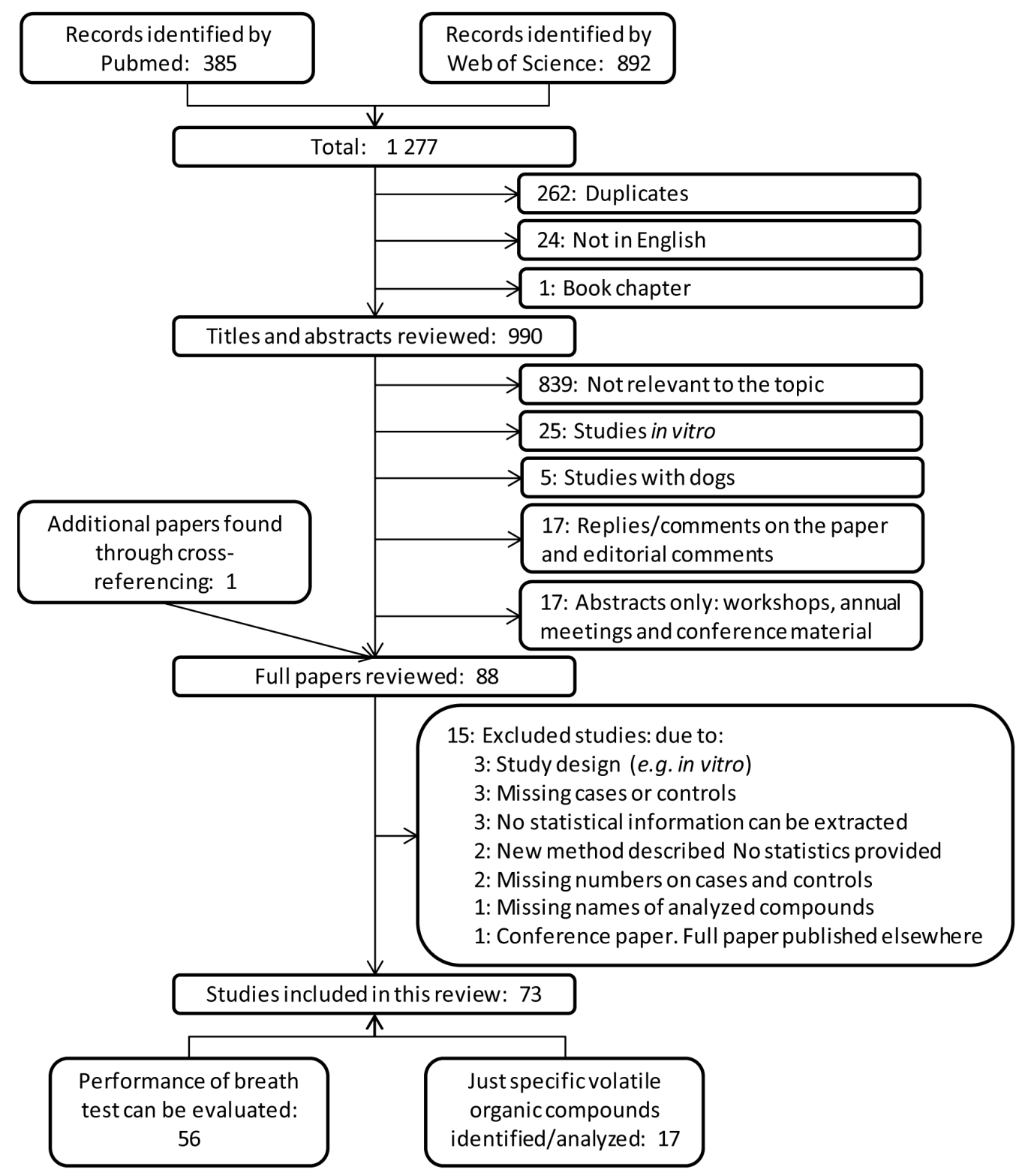

Figure 1: Flow diagram for literature search process. Flow diagram for literature search process in Pubmed and Web of Science databases using following keywords: (cancer OR carcinoma OR adenocarcinoma OR tumor OR malignancy OR malignant disease) AND ((volatile AND (compound OR compounds OR marker OR markers OR biomarker OR biomarkers)) OR VOC OR VOCs OR breathprint OR breath-print OR breath print) AND (breath OR exhaled OR air). 
duplicates, 24 non-English papers and 1 book chapter. The remaining titles and abstracts were checked and studies not relevant to the topic were excluded. For 17 studies, no full paper could be accessed. Also, 15 full-text papers were excluded as some of the required information was missing (see Additional Figure S1).

In total, 73 studies met our inclusion criteria and were described in this review. The majority of them focused on malignancies in organs of the respiratory system (lung, $n=46$; head and neck, $n=4$ ) as these cancers have the biggest potential to be diagnosed by exhaled breath. Other malignancies also investigated with breath analysis included: breast cancer $(n=11)$, gastric cancer $(n=5)$, mesothelioma and colorectal cancer (each $n=3$ ), cancers of the liver, thyroid, prostate and ovaries, and hematological and gynecological cancers (each $n=1$ ).

\section{Design and methods}

Study designs and methods of analysis are described in Table 1. To analyze exhaled breath most of the studies used gas chromatography-mass spectrometry (GC-MS, $n$ $=42$ ) and/or electronic nose (e-nose, $n=24)$. The most commonly used electronic noses were gold nanoparticles sensors-based e-nose [7] from the TECHNION group (8 studies) and commercially available Cyranose 320 [8] (six studies). Breath samples were stored in different containers with Tedlar bag being the most popular.

The vast majority of studies were conducted in a case-control approach, in which clinically diagnosed patients were compared with controls without cancer. Eight studies enrolled patients coming to the hospital with some complaints for further investigations and breath samples were collected before the final diagnosis. Also, few studies investigated differences in exhaled breath composition before and after tumor resection [9-11] and VOCs released by cancer cells or tissues $[12,13]$. Differences of volatiles between Caucasians and Chinese were investigated by Amal et al. [14]. Two more studies were conducted to compare the performance of exhaled breath analysis to the performance of canine detection [15] or DNA hypermethylation in sputum [16]. Despite the differences in studies designs, we focused and extracted information related just to breath analysis part in all of the studies.

\section{Study population}

An overview on the studies and their population characteristics is shown in Additional Table S1. Studies were conducted in all parts of the world except South America and Africa. Numbers of people included into analyses varied from 14 (6 cases and 8 controls) [17] to 477 (99 cases and 378 controls) [18]. The majority of studies used healthy controls; however, a mixture of healthy controls and individuals with some medical conditions were used as a reference group in 9 studies and 8 studies exclusively used controls with benign medical conditions. Furthermore, same study populations were used in studies on lung cancer [19, 20] and [21, 22], breast cancer $[23,24]$ and mesothelioma [25, 26].

Further information on critical study design and data collection issues is presented in Additional Table $\mathrm{S} 2$. History of smoking is the main risk factor for lung cancer development; therefore, adjustment for smoking status between cases and controls is crucial. However, 8 studies on lung cancer did not provide information on smoking status at all. The majority of the studies collected alveolar breath, 12 studies focused on collecting maximum amount of exhaled breath (vital capacity) and 7 studies on collecting tidal breath. Also, around $25 \%$ of the studies did not perform lung washout or ambient air was not analyzed which might lead to exogenous (inhaled) compounds to be included into classification models. Time between breath collection and analysis was very short (analysis done immediately or within few hours) in most studies but extended up to six months in one study [18]. Although most of the studies included newly diagnosed untreated cancer patients, few studies recruited patients under different treatment regimens, and treatment might have had an influence on exhaled volatiles.

\section{Performance of classification models}

Table 2 presents studies which reported sensitivity and specificity or other statistical information on classification of cancer cases and controls based on exhaled breath analysis. Only studies where classification based on pattern recognition by e-nose or modeling of multiple VOCs were included in this table $(n=48)$. Overall, numbers of VOCs included in the classification models varied from 3 [27-29] to 30 [20,30].

For lung cancer reported sensitivity (specificity) varied from $51 \%(13 \%)$ to $100 \%(100 \%)$. However, rigorous validation was not performed in all of the studies, which may have led to overoptimistic results. This particularly applies to two studies that reported perfect discrimination between cases and controls, with $100 \%$ overall accuracy $[28,31]$. Nevertheless, very good diagnostic performance was also reported in studies with validation showing AUCs of 0.97 [32] and 0.986 [33], or overall accuracy of $96 \%[34,35]$. Two studies applied a different classification rule and classified participants "positive" when 2 or more out of 4 VOCs had higher concentrations than the set cut-offs and found relatively high levels of accuracies of 90\% [36] and 85\% [37]. Also, two classification models on the same study population showed exactly same performance while including 4 [21] and 8 [22] VOCs. Both classification models included the same three VOCs (1-propanol, 2-butanone, benzaldehyde), which were not used together by any other study. 
Table 1: Study characteristics: breath analysis technique, breath collection system or storage container and classifier.

\begin{tabular}{|c|c|c|c|}
\hline First author, year & Technique & Storage container & Classifier ${ }^{\mathrm{a}}$ \\
\hline \multicolumn{4}{|c|}{ Studies which used electronic nose } \\
\hline Di Natale, 2003 [9] & LibraNose & Sterile disposable bag & Partial least square DA \\
\hline Chen, 2005 [74] & SAW sensors & Tedlar bag & Artificial neural networks \\
\hline Machado, 2005 [75] & Cyranose 320 & Mylar bag & Support vector machine \\
\hline Mazzone, 2007 [76] & colorimetric sensors & No storing of samples & Random forest \\
\hline Dragonieri, 2009 [77] & Cyranose 320 & Tedlar bag & Linear canonical DA \\
\hline D'Amico, 2010 [78] & QMS sensors & Tedlar bag & Partial least square DA \\
\hline Shuster, 2011 [79] & NA-NOSE & No information & Support vector machine \\
\hline Yu, $2011[80]$ & MOS sensors & Tedlar bag & Principle component analysis \\
\hline Chapman, 2012 [39] & Cyranose 320 & Rapak bag & Linear canonical DA \\
\hline Dragonieri, 2012 [26] & Cyranose 320 & Tedlar bag & Canonical DA \\
\hline Mazzone, 2012 [81] & colorimetric sensors & No storing of samples & Multinomial linear RA \\
\hline Santonico, 2012 [82] & QMS sensors & Tedlar bag & Partial least square DA \\
\hline Wang D, 2012 [83] & MOS-SAW sensors & Tedlar bag & Artificial neural networks \\
\hline Broza, $2013[11]^{b}$ & NA-NOSE & Mylar bag & Discriminant factor analysis \\
\hline Hubers, 2014 [16] & Cyranose 320 & Tedlar bag & Multinomial linear RA \\
\hline Leunis, 2014 [84] & DiagNose & Tedlar bag & Multinomial linear RA \\
\hline McWilliams, 2015 [85] & Cyranose 320 & Mylar bag & Discriminant factor analysis \\
\hline Shehada, 2015 [86] & TPS-SiNW FET sensors & ORBO 420 Tenax TA sorption tubes & Discriminant factor analysis \\
\hline \multicolumn{4}{|c|}{ Studies which used electronic nose and gas chromatography-mass spectrometry } \\
\hline Hakim, $2011[34]$ & NA-NOSE, SPME/GC-MS & Mylar bag & Support vector machine \\
\hline Peled, $2012[33]^{\mathrm{b}}$ & NA-NOSE, SPME/GC-MS & ORBO 420 Tenax TA sorption tubes & Discriminant factor analysis \\
\hline $\mathrm{Xu} Z, 2013[40]^{\mathrm{b}}$ & NA-NOSE, GC-MS & ORBO 420 Tenax TA sorption tubes & Discriminant factor analysis \\
\hline Gruber, 2014 [87] & NA-NOSE, GC-MS & ORBO 420 Tenax TA sorption tubes & Discriminant factor analysis \\
\hline Amal, 2015 ${ }^{\mathrm{OC}}[88]$ & NA-NOSE, GC-MS & ORBO 420 Tenax TA sorption tubes & Discriminant factor analysis \\
\hline Amal, $2015^{\mathrm{GC}}[18]$ & NA-NOSE, TD-GC-MS & ORBO 420 Tenax TA sorption tubes & Discriminant factor analysis \\
\hline \multicolumn{4}{|c|}{ Studies which used gas chromatography-mass spectrometry } \\
\hline Gordon, 1985 [28] & TD-GC-MS & Teflon sampling bag & Linear DA \\
\hline Preti, 1988 [44] & TD-GC-MS & Tenax sorption tubes & - \\
\hline Phillips, $1999[89]^{\mathrm{b}}$ & TD-GC-MS & Portable electrical device $^{\mathrm{c}}$ & $\mathrm{DA}$ \\
\hline Phillips, $2003^{\mathrm{BC}}[24]^{\mathrm{b}}$ & TD-GC-MS & Portable electrical device $^{\mathrm{c}}$ & DA \\
\hline Phillips, $2003^{\mathrm{LC}}[66]^{\mathrm{b}}$ & TD-GC-MS & Portable electrical device $^{\mathrm{c}}$ & DA \\
\hline Poli, $2005[10]$ & SPME/TD-GC-MS & bio-VOC breath sampler & Multinomial linear RA \\
\hline Phillips, $2006[23]^{\mathrm{b}}$ & TD-GC-MS & Portable electrical device $^{c}$ & Fuzzy logic \\
\hline Phillips, 2007 [19] & TD-GC-MS & Portable electrical device $^{c}$ & Fuzzy logic \\
\hline Phillips, 2008 [20] & TD-GC-MS & Portable electrical device $^{\mathrm{c}}$ & Weighted digital analysis \\
\hline Bajtarevic, 2009 [21] & SPME/GC-MS & Tedlar bag & - \\
\hline Ligor, 2009 [22] & SPME/GC-MS & Tedlar bag & - \\
\hline Peng, 2009 [90] & SPME/GC-MS & Mylar bag & - \\
\hline de Genaro, 2010 [25] & TD-GC-MS & Tedlar bag & Discriminant factor analysis \\
\hline Fuchs, 2010 [65] & SPME/GC-MS & Sealed headspace vial & - \\
\hline Kischkel, 2010 [91] & SPME/GC-MS & Sealed headspace vial & - \\
\hline Peng, 2010 [49] & SPME/GC-MS & Mylar bag & - \\
\hline Phillips, 2010 [30] & TD-GC-MS & Portable electrical device $^{c}$ & Weighted digital analysis \\
\hline Poli, 2010 [53] & SPME/GC-MS & bio-VOC breath sampler & DA \\
\hline
\end{tabular}




\begin{tabular}{|c|c|c|c|}
\hline First author, year & Technique & Storage container & Classifier $^{\mathrm{a}}$ \\
\hline Qin, 2010 [27] & SPME/TD-GC-MS & Tedlar bag & Fisher's linear DA \\
\hline Song, 2010 [29] & SPME/GC-MS & Tedlar bag & - \\
\hline Patterson, 2011 [92] & TD-GC-MS & Teflon sampling bag & $\begin{array}{l}\text { Linear DA, Quadratic DA, } \\
\text { support vector machine }\end{array}$ \\
\hline Rudnicka, 2011 [93] & SPME/GC-TOF-MS & Tedlar bag & Discriminant factor analysis \\
\hline Ulanowska, 2011 [94] & SPME/GC-MS & Tedlar bag & $\mathrm{DA}$ \\
\hline Buszewski, 2012 [15] & SPME/GC-MS & Tedlar bag & - \\
\hline Mangler, 2012 [95] & TD-GC-MS & Tenax test tube & - \\
\hline Wang Y, 2012 [13] & SPME/GC-MS & Tedlar bag & Linear DA \\
\hline Amal, $2013[14]$ & TD-GC-MS & ORBO 420 Tenax TA sorption tubes & - \\
\hline Altomare, 2013 [96] & TD-GC-MS & Tedlar bag & Probabilistic neural networks \\
\hline Filipiak, 2014 [12] & TD-GC-MS & Tedlar bag & - \\
\hline Garcia, 2014 [97] & SPME/GC-MS & Tedlar bag & - \\
\hline Li, $2014[98]$ & SPME/GC-MS & Tedlar bag & Fisher's DA \\
\hline Rudnicka, 2014 [32] & SPME/GC-MS & Tedlar bag & Artificial neural networks \\
\hline Wang C, 2014 ${ }^{\mathrm{BC}}[99]$ & SPME/GC-MS & Glass vials & Partial least square DA \\
\hline Wang C, 2014 ${ }^{\mathrm{CRC}}[100]$ & SPME/GC-MS & Glass vials & Partial least square DA \\
\hline Zou, 2014 [41] & SPME/GC-MS & Tedlar bag & - \\
\hline Guo, 2015 [101] & SPME/GC-MS & Glass vials & - \\
\hline \multicolumn{4}{|c|}{ Studies which used other techniques } \\
\hline Hietanen, 1994 [102] & $\begin{array}{l}\text { Carbotrap/Carbosieve } \\
\text { SIII-TD-GC } \\
\end{array}$ & Vacu-sampler can & - \\
\hline Rieder, 2001 [103] & PTR-MS & No storing of samples & - \\
\hline Steeghs, 2007 [104] & PTR-MS & Tedlar bag & Logistic RA \\
\hline Wehinger, 2007 [35] & PTR-MS & Tedlar bag & Fisher's quadratic DA \\
\hline Westhoff, 2009 [31] & MCC/IMS & No storing of samples & Linear DA \\
\hline Hauschild, 2012 [62] & MCC/IMS & No storing of samples & Random forest \\
\hline Bousamra, 2014 [37] & FT-ICR-MS & Tedlar bag & Ruled \\
\hline $\mathrm{Fu}, 2014[36]$ & FT-ICR-MS & Tedlar bag & Ruled \\
\hline Handa, 2014 [105] & MCC/IMS & No storing of samples & Decision Tree \\
\hline Ma, $2014[106]$ & SPME/GCxGC & Tedlar bag & - \\
\hline Phillips, $2014[38]^{\mathrm{b}}$ & GC-SAW & Portable electrical devicec & Weighted digital analysis \\
\hline $\mathrm{Xu} \mathrm{H}, 2014$ [17] & MSPE & RTube collection system & - \\
\hline Kumar, 2015 [107] & SIFT-MS & Nalophan & Logistic RA \\
\hline
\end{tabular}

${ }^{a}$ missing classifier identifies studies where no diagnostic performance of breath test was evaluated but concentrations of volatile compounds between cases and controls were compared; ${ }^{b}$ patients attending the hospital with some complain were enrolled in the study and breath samples were collected before the final diagnosis; ' - at least 2 out of 4 elevated VOCs present in breath; ${ }^{\mathrm{GC}}$ Gastric cancer; ${ }^{\mathrm{OC}}$ Ovarian cancer; ${ }^{\mathrm{LC}}$ Lung cancer; ${ }^{\mathrm{BC}} \mathrm{Breast}$ cancer; ${ }^{\mathrm{CRC}}$ Colorectal cancer.

METHODS: GC - gas chromatography; MS - mass spectrometry; FT-ICR-MS - Fourier transform ion cyclotron resonance MS; GC-TOF-MS - GC-Time of flight-MS; MCC/IMS - multi capillary column-ion mobility spectrometry; MOS - metal oxide semiconductor; MSPE - magnetic solid-phase extraction; TD-GC-MS - thermal desorption-GC-MS; PTR-MS - proton transfer reaction-MS; QMS - quartz microbalance; SAW - surface acoustic wave; SIFT-MS - selected ion flow tube-MS; SPME - solid phase microextraction; TPS-SiNW-FET - trichloro-(phenethyl)silane-silicon nanowire-field effect transistor. CLASIFIER: DA - discriminant analysis; RA - regression analysis. 
Table 2: Breath test performance for cancer detection together with indication if values were corrected for overoptimism.

\begin{tabular}{|c|c|c|c|c|c|c|c|}
\hline First author, year & $\operatorname{Cs}(\mathrm{N})$ & $\operatorname{Cn}(\mathrm{N})$ & Sens & Spec & AUC & Acc & Corrected for overoptimism?a \\
\hline \multicolumn{8}{|l|}{ Lung cancer } \\
\hline \multirow{2}{*}{ Gordon, 1985 [28] } & 12 & 9 & - & - & - & 93.0 & NO-model on selected 3 VOCs \\
\hline & 12 & 9 & 100.0 & 100.0 & - & 100.0 & NO-model on selected 22 VOCs \\
\hline Phillips, 1999 [89] & 60 & 48 & 71.7 & 66.7 & - & 69.4 & YES-LOOCV \\
\hline \multirow{2}{*}{ Phillips, 2003 [66] } & 67 & 41 & 85.1 & 80.5 & - & 83.3 & YES-LOOCV \\
\hline & - & $91^{\mathrm{b}}$ & - & 37.4 & - & - & YES-validation set \\
\hline Chen, 2005 [74] & 5 & 5 & 80.0 & 80.0 & - & 80.0 & YES-validation set \\
\hline Machado, 2005 [75] & 14 & 62 & 71.4 & 91.9 & - & 88.2 & YES-validation set \\
\hline Poli, 2005 [10] & 36 & 110 & 72.2 & 93.6 & - & 88.4 & NO-model on selected VOCs \\
\hline Mazzone, 2007 [76] & 49 & 94 & 73.3 & 72.4 & - & - & YES-RSS-70:30\% \\
\hline Phillips, 2007 [19] & 193 & 211 & 84.6 & 80.0 & 0.88 & - & YES-RSS-2:1 \\
\hline Steeghs, 2007 [104] & 11 & 57 & - & - & 0.81 & - & NO-model on selected VOCs \\
\hline Wehinger, 2007 [35] & 17 & 170 & 54.0 & 99.0 & - & 96.0 & YES-average of 1.000 RSS- $60: 40 \%$ \\
\hline Phillips, 2008 [20] & 193 & 211 & - & - & 0.87 & - & NO-VOCs preselected, then RSS \\
\hline \multirow{3}{*}{ Bajtarevic, 2009 [21] } & 65 & 31 & 52.0 & 100.0 & - & - & NO-model on selected 4 VOCs \\
\hline & 65 & 31 & 71.0 & 100.0 & - & - & NO-model on selected 15 VOCs \\
\hline & 65 & 31 & 80.0 & 100.0 & - & - & NO-model on selected 21 VOCs \\
\hline \multirow{2}{*}{ Dragonieri, 2009 [77] } & 10 & 10 & - & - & - & 90.0 & \multirow{2}{*}{ YES-cross-validation } \\
\hline & 10 & $10^{\mathrm{c}}$ & - & - & - & 85.0 & \\
\hline Ligor, 2009 [22] & 65 & 31 & 51.0 & 100.0 & - & - & NO-model on selected 8 VOCs \\
\hline Westhoff, 2009 [31] & 32 & 54 & 100.0 & 100.0 & - & 100.0 & NO-first VOCs selected, then LOOCV \\
\hline \multirow{2}{*}{ D'Amico, 2010 [78] } & 28 & 36 & 85.0 & 100.0 & - & 93.8 & \multirow{2}{*}{ YES-LOOCV } \\
\hline & 28 & $28^{\mathrm{d}}$ & 92.8 & 78.6 & - & 85.7 & \\
\hline Poli, 2010 [53] & 40 & 38 & 90.0 & 92.1 & - & 91.0 & YES-LOOCV \\
\hline Hakim, $2011[34]$ & 20 & 26 & 100.0 & 92.3 & - & 95.7 & YES-average of all sample splits \\
\hline $\mathrm{Yu}, 2011[80]$ & 9 & 9 & 100.0 & 88.9 & - & 94.4 & NO-model on selected peaks \\
\hline \multirow{2}{*}{ Mazzone, 2012 [81] } & $83 \mathrm{e}$ & 137 & - & - & 0.701 & - & \multirow{2}{*}{ NO-model on selected sensor parameters } \\
\hline & $9 f$ & 137 & - & - & 0.8 & - & \\
\hline Peled, 2012 [33] & 50 & 19 & 86.0 & 96.0 & 0.986 & 88.0 & YES-LOOCV \\
\hline Santonico, 2012 [82] & 20 & 10 & 85.0 & 85.0 & - & 85.0 & YES-LOOCV \\
\hline Wang D, 2012 [83] & 47 & 42 & 93.6 & 83.4 & - & 88.8 & YES-LOOCV \\
\hline Wang Y, 2012 [13] & 85 & 158 & 96.5 & 97.5 & - & 97.1 & YES-LOOCV \\
\hline Broza, 2013 [11] & 12 & 5 & 100.0 & 80.0 & & 94.1 & YES-LOOCV \\
\hline Bousamra, 2014 [37] & 107 & 40 & 87.9 & 77.5 & - & 85.0 & $\begin{array}{l}\text { YES- } \geq 2 \text { out of } 4 \text { elevated VOCs } \\
\text { present (VOCs selected on the different } \\
\text { population) }\end{array}$ \\
\hline $\mathrm{Fu}, 2014[36]$ & 97 & 32 & 92.8 & 81.3 & - & 89.9 & NO- $\geq 2$ out of 4 elevated VOCs present \\
\hline Handa, 2014 [105] & 50 & 39 & 76.0 & 100.0 & - & - & NO-model on selected $10 \mathrm{VOCs}$ \\
\hline Hubers, 2014 [16] & 18 & 8 & 94.4 & 12.5 & - & 69.2 & YES-validation set \\
\hline Rudnicka, 2014 [32] & 108 & 121 & 74.0 & 73.0 & 0.97 & - & YES-RSS-50:25:25\% \\
\hline McWilliams, 2015 [85] & 25 & 166 & - & - & 0.803 & - & YES-average of 10 RSS-2:1 \\
\hline \multicolumn{8}{|l|}{ Breast cancer } \\
\hline \multirow{2}{*}{ Phillips, 2003 [24] } & 51 & 42 & 88.2 & 73.8 & - & 81.7 & \multirow{2}{*}{ YES-LOOCV } \\
\hline & 51 & $50^{\mathrm{g}}$ & 60.8 & 82.0 & - & 71.3 & \\
\hline \multirow{2}{*}{ Phillips, 2006 [23] } & 51 & 42 & 93.8 & 84.6 & 0.9 & - & YES-RSS-70:30\% \\
\hline & - & $50^{\mathrm{g}}$ & - & 32.0 & - & - & YES-validation set \\
\hline
\end{tabular}




\begin{tabular}{|c|c|c|c|c|c|c|c|}
\hline First author, year & Cs (N) & Cn (N) & Sens & Spec & AUC & Acc & Corrected for overoptimism?a \\
\hline Phillips, $2010[30]$ & 54 & 204 & 75.3 & 84.8 & 0.83 & - & YES-10 RSS-2:1 \\
\hline Patterson, 2011 [92] & 20 & 20 & 72.0 & 64.0 & - & 77.0 & YES-average of 10.000 RSS- $60: 40 \%$ \\
\hline $\mathrm{Li}, 2014$ [98] & 22 & 24 & 68.2 & 91.7 & - & 80.4 & YES-LOOCV \\
\hline \multirow{2}{*}{ Phillips, 2014 [38] } & 35 & 93 & - & - & 0.73 & - & \multirow{2}{*}{ YES-LOOCV } \\
\hline & 35 & $79^{\mathrm{g}}$ & - & - & 0.67 & - & \\
\hline \multicolumn{8}{|c|}{ Colorectal $^{\mathrm{CRC}}$, gastric ${ }^{\mathrm{GC}}$, ovarian ${ }^{\mathrm{OC}}$, liver ${ }^{\mathrm{LVC}}$, head and neck $^{\mathrm{HNC}}$ cancer and malignant mesothelioma $^{\mathrm{MM}}$} \\
\hline \multirow{2}{*}{ Qin, 2010 ${ }^{\mathrm{LVC}}[27]$} & 30 & 36 & 83.3 & 91.7 & - & 87.9 & \multirow{2}{*}{$\begin{array}{l}\begin{array}{l}\text { NO-first } \\
\text { LOOCV }\end{array} \\
\text { VOCs selected, then }\end{array}$} \\
\hline & - & $27^{\mathrm{h}}$ & - & 66.7 & - & - & \\
\hline Hakim, 2011 ${ }^{\mathrm{HNC}}[34]$ & 16 & 26 & 100.0 & 92.3 & - & 95.2 & YES-average of all sample splits \\
\hline \multirow{2}{*}{ Chapman, 2012 ${ }^{\mathrm{MM}}[39]$} & 20 & 42 & 90.0 & 91.0 & - & 90.5 & $\begin{array}{l}\begin{array}{l}\text { YES-RSS } \\
\text { validation })\end{array} \\
\text { vallo } \\
\end{array}$ \\
\hline & - & $18^{\mathrm{d}}$ & - & 83.3 & - & - & YES-validation set \\
\hline \multirow{2}{*}{ Dragonieri, 2012 ${ }^{\mathrm{MM}}$ [26] } & 13 & 13 & - & - & 0.893 & 84.6 & \multirow{2}{*}{ YES-LOOCV } \\
\hline & 13 & $13^{\mathrm{i}}$ & - & - & 0.917 & 80.8 & \\
\hline Altomare, 2013 ${ }^{\mathrm{CRC}}[96]$ & 15 & 10 & 80.0 & 70.0 & - & 76.0 & YES-validation set \\
\hline $\mathrm{Xu}$ Z, 2013GC [40] & 37 & 93 & 89.0 & 90.0 & - & 90.0 & YES-RSS-75:25\% \\
\hline \multirow{2}{*}{ Gruber, 2014 ${ }^{\mathrm{HNC}}[87]$} & 22 & 19 & 77.0 & 90.0 & - & 83.0 & \multirow{2}{*}{ YES-LOOCV } \\
\hline & 22 & $21^{\mathrm{j}}$ & 77.0 & 90.0 & - & 84.0 & \\
\hline Leunis, 2014 ${ }^{\mathrm{HNC}}[84]$ & 36 & 23 & - & - & 0.85 & - & YES-bootstrapped value \\
\hline \multirow{3}{*}{ Amal, 2015 ${ }^{\mathrm{OC}}$ [88] } & 48 & 48 & 78.6 & 100.0 & - & 89.3 & \multirow{3}{*}{ YES-RSS-70:30\% } \\
\hline & 48 & $86^{\mathrm{k}}$ & 57.1 & 59.0 & - & 58.0 & \\
\hline & 48 & $134^{1}$ & 71.4 & 71.8 & - & 71.7 & \\
\hline \multirow{2}{*}{ Amal, 2015 } & 99 & $325^{\mathrm{m}}$ & 73.3 & 97.9 & - & 92.0 & \multirow{2}{*}{ YES-RSS-70:30\% } \\
\hline & 99 & $53^{\mathrm{n}}$ & 86.7 & 86.7 & - & 86.7 & \\
\hline Kumar, 2015 $5^{\mathrm{GC}}[107]$ & 81 & 121 & 86.7 & 81.2 & 0.87 & - & YES-average of 10 RSS-2:1 \\
\hline Shehada, 2015 ${ }^{\mathrm{GC}}[86]$ & 30 & 77 & 71.0 & 89.0 & - & 85.0 & YES-RSS-75:25\% \\
\hline
\end{tabular}

$\mathrm{Cn}$ - cases; Cs - controls, N - number of cases/controls; Sens - sensitivity; Spec - specificity; AUC - area under the receiver operating characteristic curve; RSS - random sample split-training set size: testing set size: validation set size. Numbers of cases and controls are total study population size and performance of breath test corresponds to testing (validation) set; LOOCV - leave-one-out cross-validation; VOCs-volatile organic compounds.

${ }^{a} \mathrm{NO}$ indicates studies which used same study population for model building and testing; ${ }^{b}$ abnormal X-rays, no cancer; ${ }^{\mathrm{c}} \mathrm{Chronic}$ obstructive pulmonary disease; ${ }^{\mathrm{d}}$ lung diseases; ${ }^{\mathrm{P}}$ non-small cell lung cancer; ${ }^{\mathrm{f}}$ small cell lung cancer; ${ }^{\mathrm{g}}$ abnormal mammography; hhepatoccirosis; ' exposed to asbestos; ${ }^{\text {b }}$ benign head and neck conditions; ' ovarian benign conditions; 'healthy+ovarian benign conditions; ${ }^{\mathrm{m}}$ Operative link on gastric intestinal metaplasia assessment stage 0-IV; " gastric ulcer.

Six studies reported the diagnostic performance of breath test for distinguishing breast cancer patients and healthy controls. The best discriminatory performance was achieved by Phillips et al. in 2006 [23], who reported AUC of 0.9. On the other hand, the same model validated in women with abnormal mammography findings showed specificity as low as $32 \%$. Other studies by the same authors also showed better performance of the classification models when comparing cancer cases to healthy women rather than to women with abnormal mammography findings [24, 38].

Good diagnostic performance was also reported in most of the studies focusing on the cancer organs other than lung and breast, and AUC or accuracy of 0.9 or higher was reported in studies on head and neck cancer
[34], malignant mesothelioma [39], and gastric cancer [18, 40].

\section{Performance of individual VOCs}

The performance of classification using individual VOCs as cancer biomarkers in exhaled breath was reported in 8 studies and is presented in Table 3. Several volatiles, i.e., 3-hydroxybutan-2-one, showed promising results for different cancer sites. One study validated its results in a different population sample and showed superb performance of hexadecanal $(\mathrm{AUC}=1.00)$ [41]. Volatile organic compounds which were used to build a classification model or whose concentrations were significantly different between cancer cases and controls 
Table 3: Performance of the individual compounds together with the concentration gradient in the cancer patients.

\begin{tabular}{|c|c|c|c|c|c|c|c|}
\hline First author, year & \begin{tabular}{|l}
$\begin{array}{l}\text { Cancer } \\
\text { site }\end{array}$ \\
\end{tabular} & Volatile compound & Cut-off & Sens & Spec & AUC & Gradient \\
\hline \multirow{4}{*}{ Fuchs, 2010 [65] } & \multirow{4}{*}{ lung } & pentanal & $0.275 \mathrm{nmol} / \mathrm{L}$ & 75.0 & 95.8 & - & up \\
\hline & & hexanal & $1.208 \mathrm{nmol} / \mathrm{L}$ & 8.3 & 91.7 & - & up \\
\hline & & octanal & $1.068 \mathrm{nmol} / \mathrm{L}$ & 58.3 & 91.7 & - & up \\
\hline & & nonanal & $8.433 \mathrm{nmol} / \mathrm{L}$ & 33.3 & 95.8 & - & up \\
\hline \multirow{2}{*}{ Song, 2010 [29] } & \multirow{2}{*}{ lung } & butan-1-ol & $3.67 \mathrm{ng} / \mathrm{L}$ & 95.3 & 85.4 & 0.94 & up \\
\hline & & 3-hydroxybutan-2-one & $3.81 \mathrm{ng} / \mathrm{L}$ & 93.0 & 92.7 & 0.96 & up \\
\hline Wang Y, 2012 [13] & lung & hexadecanal & $?$ & 96.5 & 89.2 & 0.949 & - \\
\hline Handa, 2014 [105] & lung & dodecane & $?$ & 70.0 & 89.7 & - & up \\
\hline \multirow{5}{*}{ Zou, $2014[41]^{\mathrm{a}}$} & \multirow{5}{*}{ lung } & 5-(2-methylpropyl)nonane & $?$ & - & - & 0.845 & up \\
\hline & & 2,6-di-tert-butyl-4-methylphenol & $?$ & - & - & 0.724 & up \\
\hline & & 2,6,11-trimethyldodecane & $?$ & - & - & 0.846 & up \\
\hline & & hexadecanal & $?$ & - & - & 1.00 & up \\
\hline & & 8-hexylpentadecane & $?$ & - & - & 0.672 & up \\
\hline \multirow{5}{*}{ Mangler, 2012 [95] } & \multirow{5}{*}{ breast } & 3-methylhexane & $-0.55 \mu \mathrm{g} / \mathrm{m}^{3}$ & 100.0 & 40.0 & - & down \\
\hline & & dec-1-ene & $-0.125 \mu \mathrm{g} / \mathrm{m}^{3}$ & 100.0 & 40.0 & - & down \\
\hline & & Caryophyllene $^{\mathrm{b}}$ & $-0.05 \mu \mathrm{g} / \mathrm{m}^{3}$ & 100.0 & 60.0 & - & down \\
\hline & & naphthalene & $0.05 \mu \mathrm{g} / \mathrm{m}^{3}$ & 90.0 & 70.0 & - & down \\
\hline & & trichloroethene & $0.05 \mu \mathrm{g} / \mathrm{m}^{3}$ & 80.0 & 70.0 & - & up \\
\hline \multirow{4}{*}{ Li, 2014 [98] } & \multirow{4}{*}{ breast } & hexanal & $10.32 \mathrm{ppbv}$ & 77.3 & 79.2 & 0.79 & up \\
\hline & & heptanal & $9.98 \mathrm{ppbv}$ & 68.2 & 91.7 & 0.823 & up \\
\hline & & octanal & $12.9 \mathrm{ppbv}$ & 63.6 & 87.5 & 0.734 & up \\
\hline & & nonanal & $23.14 \mathrm{ppbv}$ & 72.7 & 95.8 & 0.832 & up \\
\hline \multirow{3}{*}{ Qin, $2010[27]^{\mathrm{c}}$} & \multirow{3}{*}{ liver } & 3-hydroxybutan-2-one & $2.44 \mathrm{ng} / \mathrm{L}$ & 83.3 & 91.7 & 0.926 & up \\
\hline & & ethenylbenzene & $14.92 \mathrm{ng} / \mathrm{L}$ & 66.7 & 94.4 & 0.812 & up \\
\hline & & decane & $1.64 \mathrm{ng} / \mathrm{L}$ & 86.7 & 58.3 & 0.798 & up \\
\hline
\end{tabular}

Sens - sensitivity; Spec - specificity; AUC - area under the receiver operating characteristic curve; ppbv - parts per billion by volume.

aperformance in the validation set; ${ }^{\mathrm{b}} 4,11,11$-trimethyl-8-methylidenebicyclo[7.2.0] undec-4-ene; ${ }^{\mathrm{c}}$ comparison between liver cancer patients and healthy controls.

in at least three independent studies are presented in Additional Table S3. Ethenylbenzene (styrene), heptanal and nonanal were the most commonly described compounds (each in 9 independent studies). Interestingly, these studies were performed on different cancer types. By contrast, 1-propanol was described just by the studies on lung cancer, 3 studies showed significantly different concentrations in exhaled breath and 4 others included this compound in classification models.

\section{DISCUSSION}

In this paper, we present a comprehensive up to date overview of studies on diagnostic performance of VOCs in cancer detection. Our review identified 73 studies which used breath analysis for classification of cancer cases and controls or analyzed specific VOCs in exhaled breath of cancer patients and healthy individuals. The majority of the studies focused on lung cancer; however, recent reports addressed other common malignancies including breast, gastric and other types of cancer. Very good diagnostic performance of breath tests was achieved, but one out of four studies lacked appropriate correction for overoptimism. It is worth pointing out, that studies differed significantly with respect to breath analysis techniques and data analysis methods. Based on current evidence, VOCs seem to hold a great potential in cancer diagnostics; nevertheless, the ultimate role of these markers for cancer screening needs to be determined and established in large scale studies conducted in true screening setting.

Breath analysis is a young field of research and majority of the studies were performed in recent years. That hundreds of VOCs are present in human breath is known for decades [42]. In the 1980s, the first studies reported higher levels of some volatiles in the breath of lung cancer patients $[28,43,44]$ and these studies 
fostered substantial interest in research of cancer specific biomarkers in breath. The first studies focused on identifying specific volatile organic compounds for diseases of interest using methods such as GC-MS, which is expensive, time-consuming and requires well-trained personnel for performing sample collection and analysis. Furthermore, identification of detected compounds is not straight forward and reference libraries have to be checked and validated using mass and retention time of the known standards. The latter, among other reasons, led researchers to look for different methods to analyze exhaled breath, one such technology is the nanomaterial-based sensor arrays that could be a good solution for solving the problems mentioned above [45-47].

As the main difference from standard analytic techniques, electronic nose mimics mammalian olfaction [48] and in that it cannot distinguish specific VOCs but is based on pattern recognition. First, the e-nose needs to be trained to build a database for recognition, and then it can be applied for classifying other unknown samples. The crucial factors of meaningful pattern recognition are the size of the training set and how good these samples represent tested populations. As one way to improve the performance of e-nose, a combination between other techniques and e-nose is possible, i.e. specific VOCs can be identified by GC-MS and used to select sensors most sensitive to target compounds [49].

Independent of analysis techniques, breath sample collection and storage are major challenges in breath research studies. The stability of compounds in different bags have been investigated [50-52], which showed that some polar compounds, including water, diffuse rather quickly through Tedlar bag walls, while other compounds are quite stable. Aldehydes were shown to be rather stable in Bio-VOC sampler in the first 10 hours after collection while analysis was done in less than 2 hours [53]. Sample storage time recorded in this review was very short and those five studies which exceeded few months for storage, used thermal sorption tubes which are suitable for longterm storing [54]. Apart from loss of compounds due to diffusion through the bags' walls, some compounds might be released by the bags material and accumulate in the collected air sample [55]. Reusing the same bag might represent another challenge as flushing and heating failed to remove some of the compounds from Tedlar bag [56]. Finally, concentration of VOCs also strongly depends on breath collection method. Alveolar breath has higher levels of exhaled components than the whole breath without separation [57, 58] and also the lowest concentrations of contaminants [59]. Standardization of the breath collection process appears crucial for further advances in breath-based biomarker research. Additionally to ambient air analysis or lung washout before breath sampling $[60,61]$, other standardization processes including recommendations for sample storage in thermal desorption tubes or ways to avoid some confounders while recruiting hospital personnel rather than healthy individuals outside the hospital were recently suggested as well [54].

A key issue in the analysis of high dimensional data such as those obtained from breath analysis is rigorous control for overoptimism by internal or external validation. External validation is particularly interesting where performance of classification model can be demonstrated on different populations or different recruitment conditions, as the purpose of marker discovery studies is their potential application in future screening strategies. Replication of the results might not be easily achieved as different methods and analysis techniques are being used by different research groups. Furthermore, different results were achieved even in the same study while applying different computational approaches for data analysis [25, 62]. Still, internal validation by performing, for example, random sample split or leave-one-out cross-validation can help to get as close to the real estimate as it can get but does not guarantee good performance on different study populations.

Adjusting for covariates when building a classification model for breath analysis is another challenge as it still remains unclear which covariates should be taken into account. Controversial results were shown for the impact of age, gender and smoking status on VOCs [31, 63-66] for standard analysis techniques. On the other hand, results of "breathprints" pattern analysis with e-nose showed to be insensitive to various covariates including the ones mentioned above [34, 49], but it remains unclear and requires further research what factors may confound study results using electronic nose. While matching or adjusting for covariates is crucial for evaluating the discriminatory potential of VOCs per se, combined use of VOCs and covariates may provide the most powerful discriminatory algorithms for screening practice.

To date, there is no "universal" tumor marker that can detect any type of cancer; however, development of the VOCs field could potentially provide a tool for unified technological approaches in cancer screening. So far, the set of identified VOC patterns varies considerably among the studies. Even though promising results have been reported for certain single markers in individual studies (i.e. hexadecanal), enhanced accuracy for classification of cancer cases and controls is likely to be achieved by the combination of several compounds. Furthermore, the same compound may not be specific for a certain cancer but it might be characteristic for several types of cancer. For example, formaldehyde (methanal) was suggested to be a potential biomarker for breast [67], prostate and bladder cancers [68]. At the same time, there is emerging evidence for cancer specific markers. A review on potential cancer specific compounds was published recently [5] in which metabolic pathways for volatiles arising from bodily fluids was explained, and furthermore the potential of these compounds to be biomarkers for cancer was discussed. 
Breath analysis as a cancer detection method and potential VOCs biomarkers for cancer were previously discussed and summarized [5,69]. Queralto et al. covered the existing evidence on exhaled breath analysis and cancer detection [70], but provided only a brief description of the results and focused mainly on differences between array-based sensors. Recently, increasing interest has been devoted to novel instruments for breath analysis. Reviews were published on different electronic noses used until then for biomedical and other applications [71], advances in breath analysis using e-nose for detection of various diseases [72] and nanosensor technologies used for VOCs detection $[45,73]$.

Differently to previous reviews, we extensively discuss key shortcomings of methodological issues, such as correction for overoptimism, performance of the validation studies and influence of potential confounders. Furthermore, we did not restrict this systematic review to specific cancer site or analysis method, as we wanted to understand exact potential of application of breath analysis to cancer detection at this stage. Nevertheless, our review has certain limitations that need to be acknowledged. Despite a comprehensive research in two independent databases we cannot exclude the possibility of having missed relevant studies. Standardized summarization and presentation of results was hampered by heterogeneity in the reporting in the original studies. We did not include in vitro studies because performance of these markers may not always translate into direct clinical applications in screening and diagnostic settings. We also did not include studies which used sniffer dogs, as potential implementation of canine-based diagnosis in health care settings might face logistic limitations.

In conclusion, breath analysis is a young field of research with great potential in cancer screening. For establishing an accurate test in a point of care screening setting, a large throughput sampling protocol of participants is required, i.e., collection and analysis time should be short, the method itself should be cheap, non-invasive, and with minimal health risk. In order to foster implementation in practice, larger studies should be implemented in true screening settings, paying particular attention to standardization in breath collection, consideration of covariates, adjustment for overoptimism, and validation in independent population samples. With further advancements in the area, breath test may have the potential to become a useful supplement and improve existing screening tools for a variety of cancers.

\section{MATERIALS AND METHODS}

A systematic literature search was performed in literature published until April 30, 2015 by searching Pubmed and Web of Science databases using the following combination of keywords: (cancer OR carcinoma OR adenocarcinoma OR tumor OR malignancy OR malignant disease) AND ((volatile AND (compound OR compounds OR marker OR markers OR biomarker OR biomarkers)) OR VOC OR VOCs OR breathprint OR breath-print OR breath print) AND (breath OR exhaled OR air). Fulltext original studies in English language which reported statistics on discrimination between cancer cases and controls, or studies which investigated specific VOCs, were included in this systematic review. In addition, reference lists were checked for relevant published studies for inclusion. Studies exclusively conducted in vitro or with sniffer dogs were not considered in this review.

Data extraction was carried out independently by two of the authors, AK and JAH, and included characteristics of study populations, such as numbers of cases and controls, their age, sex and smoking prevalence, as well as the country where study populations were recruited. Study design and methods used for breath analysis were also recorded. Indicators for diagnostic value were extracted both for individual VOCs as well as for multi-VOCs classifiers where provided. The following statistical parameters were considered: sensitivity and specificity, accuracy and area under the receiver operating characteristic curve (AUC). Correction for overoptimism and validation was recorded for each study. The most reliable information was considered to avoid overoptimism, i.e. bootstrapped or cross-validated values were extracted wherever such results were provided. For studies which used random sample split to create a model and validate it separately, values corresponding to validation set were considered.

Additionally, we extracted names of VOCs which showed a significantly different concentration in exhaled breath from cancer cases and controls, or which were used to build a classification model. The IUPAC name [6] was checked for all extracted compounds to detect synonyms and to ensure comparable results.

Missing information in the tables was calculated where possible, i.e., accuracy was assessed as the sum of correctly classified cases and controls divided by total number of people in a classification model. Also, when comparison of exhaled breath was made just between two groups (cases and controls) but authors provided a study population description for separate smaller sub-groups, then numbers were added up or weighted averages (e.g. of age) were calculated where possible.

Additionally, some quality criteria were checked for the studies and included in this systematic review. Comparability with respect to gender (or smoking status) was determined by the difference in percent units between proportion of males (or smokers) between cancer cases and controls. As for age, difference among median (or mean) ages between study groups was calculated. Comparability with respect to these variables was set to "yes" if the difference was not greater than 10 units and "no" otherwise. Other potentially important information for evaluating and comparing the results between studies 
was extracted, such as collection time and which breath part was used for analysis, analysis time, restrictions, potential preceding treatment of cancer cases, and exclusion criteria used when recruiting patients in each of the studies.

\section{ACKNOWLEDGMENTS}

We acknowledge Ms. Prudence Carr for writing assistance.

\section{FUNDING}

This manuscript was prepared in a context of the VOLGACORE project supported by the German Federal Ministry of Education and Research (Grant number 13N13059), Research Council of Lithuania and Latvia Academy of Science.

\section{CONFLICTS OF INTEREST}

The authors report no conflict of interest.

\section{REFERENCES}

1. Jemal A, Bray F, Center MM, Ferlay J, Ward E and Forman D. Global Cancer Statistics. Ca: a Cancer Journal for Clinicians. 2011; 61:69-90.

2. Ferlay JI, Soerjomataram M, Ervik R, Dikshit S, Eser C, Mathers M, Rebelo DM, Parkin FD and Bray F. (2013). GLOBOCAN 2012 v10, Cancer Incidence and Mortality Worldwide: IARC CancerBase No 11. (Lyon, France: International Agency for Research on Cancer ).

3. Horvath I and de Jongste JE. (2010). Exhaled Biomarkers: European Respiratory Society).

4. Amann A, Mochalski P, Ruzsanyi V, Broza YY and Haick H. Assessment of the exhalation kinetics of volatile cancer biomarkers based on their physicochemical properties. Journal of breath research. 2014; 8:016003.

5. Haick H, Broza YY, Mochalski P, Ruzsanyi V and Amann A. Assessment, origin, and implementation of breath volatile cancer markers. Chemical Society reviews. 2014; 43:1423-1449.

6. (1993). IUPAC Commission on the Nomenclature of Organic Chemistry, A Guide to IUPAC Nomenclature of Organic Compounds. ( Ltd., Oxford, UK: Blackwell Scientific Publications).

7. The Nanoscale Artificial NOSE.

8. (2000). Cyrano Sciences Unveils Portable Electronic Nose.

9. Di Natale C, Macagnano A, Martinelli E, Paolesse R, D'Arcangelo G, Roscioni C, Finazzi-Agro A and D'Amico A. Lung cancer identification by the analysis of breath by means of an array of non-selective gas sensors. Biosensors \& bioelectronics. 2003; 18:1209-1218.
10. Poli D, Carbognani P, Corradi M, Goldoni M, Acampa O, Balbi B, Bianchi L, Rusca M and Mutti A. Exhaled volatile organic compounds in patients with non-small cell lung cancer: cross sectional and nested short-term follow-up study. Respiratory research. 2005; 6:71.

11. Broza YY, Kremer R, Tisch U, Gevorkyan A, Shiban A, Best LA and Haick H. A nanomaterial-based breath test for short-term follow-up after lung tumor resection. Nanomedicine : nanotechnology, biology, and medicine. 2013; 9:15-21.

12. Filipiak W, Filipiak A, Sponring A, Schmid T, Zelger B, Ager C, Klodzinska E, Denz H, Pizzini A, Lucciarini $\mathrm{P}$, Jamnig H, Troppmair J and Amann A. Comparative analyses of volatile organic compounds (VOCs) from patients, tumors and transformed cell lines for the validation of lung cancer-derived breath markers. Journal of breath research. 2014; 8:027111.

13. Wang Y, Hu Y, Wang D, Yu K, Wang L, Zou Y, Zhao $\mathrm{C}$, Zhang $\mathrm{X}$, Wang $\mathrm{P}$ and Ying $\mathrm{K}$. The analysis of volatile organic compounds biomarkers for lung cancer in exhaled breath, tissues and cell lines. Cancer biomarkers : section A of Disease markers. 2012; 11:129-137.

14. Amal H, Leja M, Broza YY, Tisch U, Funka K, Liepniece-Karele I, Skapars R, Xu ZQ, Liu H and Haick H. Geographical variation in the exhaled volatile organic compounds. Journal of breath research. 2013; 7:047102.

15. Buszewski $B$, Ligor $T$, Jezierski $T$, Wenda-Piesik A, Walczak M and Rudnicka J. Identification of volatile lung cancer markers by gas chromatography-mass spectrometry: comparison with discrimination by canines. Analytical and bioanalytical chemistry. 2012; 404:141-146.

16. Hubers AJ, Brinkman P, Boksem RJ, Rhodius RJ, Witte BI, Zwinderman AH, Heideman DAM, Duin S, Koning R, Steenbergen RDM, Snijders PJF, Smit EF, Sterk PJ and Thunnissen E. Combined sputum hypermethylation and eNose analysis for lung cancer diagnosis. Journal of Clinical Pathology. 2014; 67:707-711.

17. Xu H, Wei Y, Zhu L, Huang J, Li Y, Liu F, Wang S and Liu S. Bifunctional magnetic nanoparticles for analysis of aldehyde metabolites in exhaled breath of lung cancer patients. Journal of Chromatography A. 2014; 1324:29-35.

18. Amal H, Leja M, Funka K, Skapars R, Sivins A, Ancans G, Liepniece-Karele I, Kikuste I, Lasina I and Haick H. Detection of precancerous gastric lesions and gastric cancer through exhaled breath. Gut. 2015.

19. Phillips M, Altorki N, Austin JH, Cameron RB, Cataneo RN, Greenberg J, Kloss R, Maxfield RA, Munawar MI, Pass HI, Rashid A, Rom WN and Schmitt P. Prediction of lung cancer using volatile biomarkers in breath. Cancer biomarkers : section A of Disease markers. 2007; 3:95-109.

20. Phillips M, Altorki N, Austin JH, Cameron RB, Cataneo RN, Kloss R, Maxfield RA, Munawar MI, Pass HI, Rashid A, Rom WN, Schmitt P and Wai J. Detection of lung cancer using weighted digital analysis of breath biomarkers. Clinica chimica acta; international journal of clinical 
chemistry. 2008; 393:76-84.

21. Bajtarevic A, Ager C, Pienz M, Klieber M, Schwarz K, Ligor M, Ligor T, Filipiak W, Denz H, Fiegl M, Hilbe W, Weiss W, Lukas P, Jamnig H, Hackl M, Haidenberger A, et al. Noninvasive detection of lung cancer by analysis of exhaled breath. BMC cancer. 2009; 9:348.

22. Ligor M, Ligor T, Bajtarevic A, Ager C, Pienz M, Klieber M, Denz H, Fiegl M, Hilbe W, Weiss W, Lukas P, Jamnig H, Hackl M, Buszewski B, Miekisch W, Schubert J, et al. Determination of volatile organic compounds in exhaled breath of patients with lung cancer using solid phase microextraction and gas chromatography mass spectrometry. Clinical chemistry and laboratory medicine : CCLM / FESCC. 2009; 47:550-560.

23. Phillips M, Cataneo RN, Ditkoff BA, Fisher P, Greenberg J, Gunawardena R, Kwon CS, Tietje O and Wong C. Prediction of breast cancer using volatile biomarkers in the breath. Breast cancer research and treatment. 2006; 99:1921.

24. Phillips M, Cataneo RN, Ditkoff BA, Fisher P, Greenberg J, Gunawardena R, Kwon CS, Rahbari-Oskoui F and Wong C. Volatile markers of breast cancer in the breath. The breast journal. 2003; 9:184-191.

25. de Gennaro G, Dragonieri S, Longobardi F, Musti M, Stallone G, Trizio L and Tutino M. Chemical characterization of exhaled breath to differentiate between patients with malignant plueral mesothelioma from subjects with similar professional asbestos exposure. Analytical and bioanalytical chemistry. 2010; 398:3043-3050.

26. Dragonieri S, van der Schee MP, Massaro T, Schiavulli N, Brinkman P, Pinca A, Carratu P, Spanevello A, Resta $\mathrm{O}$, Musti $\mathrm{M}$ and Sterk PJ. An electronic nose distinguishes exhaled breath of patients with Malignant Pleural Mesothelioma from controls. Lung cancer (Amsterdam, Netherlands). 2012; 75:326-331.

27. Qin T, Liu H, Song Q, Song G, Wang HZ, Pan YY, Xiong FX, Gu KS, Sun GP and Chen ZD. The screening of volatile markers for hepatocellular carcinoma. Cancer epidemiology, biomarkers \& prevention : a publication of the American Association for Cancer Research, cosponsored by the American Society of Preventive Oncology. 2010; 19:2247-2253.

28. Gordon SM, Szidon JP, Krotoszynski BK, Gibbons RD and O'Neill HJ. Volatile organic compounds in exhaled air from patients with lung cancer. Clinical chemistry. 1985; 31:1278-1282.

29. Song G, Qin T, Liu H, Xu GB, Pan YY, Xiong FX, Gu KS, Sun GP and Chen ZD. Quantitative breath analysis of volatile organic compounds of lung cancer patients. Lung cancer (Amsterdam, Netherlands). 2010; 67:227-231.

30. Phillips M, Cataneo RN, Saunders C, Hope P, Schmitt P and Wai J. Volatile biomarkers in the breath of women with breast cancer. Journal of breath research. 2010; 4:026003.

31. Westhoff M, Litterst P, Freitag L, Urfer W, Bader S and
Baumbach JI. Ion mobility spectrometry for the detection of volatile organic compounds in exhaled breath of patients with lung cancer: results of a pilot study. Thorax. 2009; 64:744-748.

32. Rudnicka J, Walczak M, Kowalkowski T, Jezierski T and Buszewski B. Determination of volatile organic compounds as potential markers of lung cancer by gas chromatographymass spectrometry versus trained dogs. Sensors and Actuators B-Chemical. 2014; 202:615-621.

33. Peled N, Hakim M, Bunn PA, Jr., Miller YE, Kennedy TC, Mattei J, Mitchell JD, Hirsch FR and Haick H. Noninvasive breath analysis of pulmonary nodules. Journal of thoracic oncology : official publication of the International Association for the Study of Lung Cancer. 2012; 7:15281533.

34. Hakim M, Billan S, Tisch U, Peng G, Dvrokind I, Marom O, Abdah-Bortnyak R, Kuten A and Haick H. Diagnosis of head-and-neck cancer from exhaled breath. British journal of cancer. 2011; 104:1649-1655.

35. Wehinger A, Schmid A, Mechtcheriakov S, Ledochowski M, Grabmer C, Gastl GA and Amann A. Lung cancer detection by proton transfer reaction mass-spectrometric analysis of human breath gas. International Journal of Mass Spectrometry. 2007; 265:49-59.

36. Fu XA, Li M, Knipp RJ, Nantz MH and Bousamra M. Noninvasive detection of lung cancer using exhaled breath. Cancer medicine. 2014; 3:174-181.

37. Bousamra M, 2nd, Schumer E, Li M, Knipp RJ, Nantz $\mathrm{MH}$, van Berkel V and Fu XA. Quantitative analysis of exhaled carbonyl compounds distinguishes benign from malignant pulmonary disease. The Journal of thoracic and cardiovascular surgery. 2014; 148:1074-1080; discussion 1080-1071.

38. Phillips M, Beatty JD, Cataneo RN, Huston J, Kaplan PD, Lalisang RI, Lambin P, Lobbes MB, Mundada M, Pappas N and Patel U. Rapid point-of-care breath test for biomarkers of breast cancer and abnormal mammograms. PloS one. 2014; 9:e90226.

39. Chapman EA, Thomas PS, Stone E, Lewis C and Yates $\mathrm{DH}$. A breath test for malignant mesothelioma using an electronic nose. The European respiratory journal. 2012; 40:448-454.

40. Xu ZQ, Broza YY, Ionsecu R, Tisch U, Ding L, Liu H, Song Q, Pan YY, Xiong FX, Gu KS, Sun GP, Chen ZD, Leja $\mathrm{M}$ and Haick H. A nanomaterial-based breath test for distinguishing gastric cancer from benign gastric conditions. British journal of cancer. 2013; 108:941-950.

41. Zou Y, Zhang X, Chen X, Hu Y, Ying K and Wang P. Optimization of volatile markers of lung cancer to exclude interferences of non-malignant disease. Cancer biomarkers : section A of Disease markers. 2014; 14:371-379.

42. Pauling L, Robinson AB, Teranishi $\mathrm{R}$ and Cary $\mathrm{P}$. Quantitative analysis of urine vapor and breath by gasliquid partition chromatography. Proceedings of the 
National Academy of Sciences of the United States of America. 1971; 68:2374-2376.

43. O'Neill HJ, Gordon SM, O'Neill MH, Gibbons RD and Szidon JP. A computerized classification technique for screening for the presence of breath biomarkers in lung cancer. Clinical chemistry. 1988; 34:1613-1618.

44. Preti G, Labows JN, Kostelc JG, Aldinger S and Daniele R. Analysis of lung air from patients with bronchogenic carcinoma and controls using gas chromatography-mass spectrometry. Journal of chromatography. 1988; 432:1-11.

45. Broza YY and Haick H. Nanomaterial-based sensors for detection of disease by volatile organic compounds. Nanomedicine : nanotechnology, biology, and medicine. 2013; 8:785-806.

46. Konvalina $G$ and Haick $H$. Sensors for breath testing: from nanomaterials to comprehensive disease detection. Accounts of chemical research. 2014; 47:66-76.

47. Tisch U and Haick H. Nanomaterials for cross-reactive sensor arrays. Mrs Bull. 2010; 35:797-803.

48. Buck L and Axel R. A novel multigene family may encode odorant receptors: a molecular basis for odor recognition. Cell. 1991; 65:175-187.

49. Peng G, Hakim M, Broza YY, Billan S, Abdah-Bortnyak R, Kuten A, Tisch U and Haick H. Detection of lung, breast, colorectal, and prostate cancers from exhaled breath using a single array of nanosensors. British journal of cancer. 2010; 103:542-551.

50. Mochalski P, King J, Unterkofler K and Amann A. Stability of selected volatile breath constituents in Tedlar, Kynar and Flexfilm sampling bags. The Analyst. 2013; 138:14051418.

51. Beauchamp J, Herbig J, Gutmann R and Hansel A. On the use of Tedlar (R) bags for breath-gas sampling and analysis. Journal of breath research. 2008; 2.

52. Mochalski P, Wzorek B, Sliwka I and Amann A. Suitability of different polymer bags for storage of volatile sulphur compounds relevant to breath analysis. Journal of chromatography B, Analytical technologies in the biomedical and life sciences. 2009; 877:189-196.

53. Poli D, Goldoni M, Corradi M, Acampa O, Carbognani P, Internullo E, Casalini A and Mutti A. Determination of aldehydes in exhaled breath of patients with lung cancer by means of on-fiber-derivatisation SPME-GC/MS. Journal of chromatography B, Analytical technologies in the biomedical and life sciences. 2010; 878:2643-2651.

54. Amann A, Miekisch W, Pleil JD, Risby TH and Schubert J. (2010). Methodological issues of sample collection and analysis of exhaled breath. (Leeds, Uk: Maney Publishing).

55. Miekisch W, Kischkel S, Sawacki A, Liebau T, Mieth M and Schubert JK. Impact of sampling procedures on the results of breath analysis. Journal of breath research. 2008; 2:026007.

56. McGarvey LJ and Shorten CV. The effects of adsorption on the reusability of Tedlar air sampling bags. AIHAJ : a journal for the science of occupational and environmental health and safety. 2000; 61:375-380.

57. Miekisch W, Schubert JK and Noeldge-Schomburg GF. Diagnostic potential of breath analysis - focus on volatile organic compounds. Clinica chimica acta; international journal of clinical chemistry. 2004; 347:25-39.

58. van den Velde S, Quirynen $\mathrm{M}$, van Hee $\mathrm{P}$ and van Steenberghe D. Differences between alveolar air and mouth air. Analytical chemistry. 2007; 79:3425-3429.

59. Schubert JK, Spittler KH, Braun G, Geiger $\mathrm{K}$ and Guttmann J. CO(2)-controlled sampling of alveolar gas in mechanically ventilated patients. J Appl Physiol (1985). 2001; 90:486-492.

60. Kneepkens CMF, Lepage G and Roy CC. The Potential of the Hydrocarbon Breath Test as a Measure of LipidPeroxidation. Free Radical Bio Med. 1994; 17:127-160.

61. Risby TH and Solga SF. Current status of clinical breath analysis. Appl Phys B-Lasers O. 2006; 85:421-426.

62. Hauschild AC, Baumbach JI and Baumbach J. Integrated statistical learning of metabolic ion mobility spectrometry profiles for pulmonary disease identification. Genetics and molecular research : GMR. 2012; 11:2733-2744.

63. Kushch I, Arendacka B, Stolc S, Mochalski P, Filipiak W, Schwarz K, Schwentner L, Schmid A, Dzien A, Lechleitner M, Witkovsky V, Miekisch W, Schubert J, Unterkofler $\mathrm{K}$ and Amann A. Breath isoprene - aspects of normal physiology related to age, gender and cholesterol profile as determined in a proton transfer reaction mass spectrometry study. Clinical Chemistry and Laboratory Medicine. 2008; 46:1011-1018.

64. Lechner M, Moser B, Niederseer D, Karlseder A, Holzknecht B, Fuchs M, Colvin S, Tilg H and Rieder J. Gender and age specific differences in exhaled isoprene levels. Respiratory Physiology \& Neurobiology. 2006; 154:478-483.

65. Fuchs P, Loeseken C, Schubert JK and Miekisch W. Breath gas aldehydes as biomarkers of lung cancer. International journal of cancer Journal international du cancer. 2010; 126:2663-2670.

66. Phillips M, Cataneo RN, Cummin AR, Gagliardi AJ, Gleeson K, Greenberg J, Maxfield RA and Rom WN. Detection of lung cancer with volatile markers in the breath. Chest. 2003; 123:2115-2123.

67. Ebeler SE, Clifford AJ and Shibamoto T. Quantitative analysis by gas chromatography of volatile carbonyl compounds in expired air from mice and human. Journal of chromatography B, Biomedical sciences and applications. 1997; 702:211-215.

68. Spanel P, Smith D, Holland TA, Al Singary W and Elder JB. Analysis of formaldehyde in the headspace of urine from bladder and prostate cancer patients using selected ion flow tube mass spectrometry. Rapid Communications in Mass Spectrometry. 1999; 13:1354-1359.

69. Szulejko JE, McCulloch M, Jackson J, McKee DL, Walker 
JC and Solouki T. Evidence for Cancer Biomarkers in Exhaled Breath. Ieee Sensors Journal. 2010; 10:185-210.

70. Queralto N, Berliner AN, Goldsmith B, Martino R, Rhodes $\mathrm{P}$ and Lim SH. Detecting cancer by breath volatile organic compound analysis: a review of array-based sensors. Journal of breath research. 2014; 8:027112.

71. Wilson $\mathrm{AD}$ and Baietto M. Advances in electronic-nose technologies developed for biomedical applications. Sensors (Basel, Switzerland). 2011; 11:1105-1176.

72. Wilson AD. Advances in electronic-nose technologies for the detection of volatile biomarker metabolites in the human breath. Metabolites. 2015; 5:140-163.

73. Adiguzel Y and Kulah H. Breath sensors for lung cancer diagnosis. Biosensors \& bioelectronics. 2015; 65:121-138.

74. Chen X, Cao MF, Li Y, Hu WJ, Wang P, Ying KJ and Pan HM. A study of an electronic nose for detection of lung cancer based on a virtual SAW gas sensors array and imaging recognition method. Measurement Science \& Technology. 2005; 16:1535-1546.

75. Machado RF, Laskowski D, Deffenderfer O, Burch T, Zheng S, Mazzone PJ, Mekhail T, Jennings C, Stoller JK, Pyle J, Duncan J, Dweik RA and Erzurum SC. Detection of lung cancer by sensor array analyses of exhaled breath. American journal of respiratory and critical care medicine. 2005; 171:1286-1291.

76. Mazzone PJ, Hammel J, Dweik R, Na J, Czich C, Laskowski D and Mekhail T. Diagnosis of lung cancer by the analysis of exhaled breath with a colorimetric sensor array. Thorax. 2007; 62:565-568.

77. Dragonieri S, Annema JT, Schot R, van der Schee MP, Spanevello A, Carratu P, Resta O, Rabe KF and Sterk PJ. An electronic nose in the discrimination of patients with non-small cell lung cancer and COPD. Lung cancer (Amsterdam, Netherlands). 2009; 64:166-170.

78. D’Amico A, Pennazza G, Santonico M, Martinelli E, Roscioni C, Galluccio G, Paolesse R and Di Natale C. An investigation on electronic nose diagnosis of lung cancer. Lung cancer (Amsterdam, Netherlands). 2010; 68:170-176.

79. Shuster G, Gallimidi Z, Reiss AH, Dovgolevsky E, Billan S, Abdah-Bortnyak R, Kuten A, Engel A, Shiban A, Tisch $\mathrm{U}$ and Haick H. Classification of breast cancer precursors through exhaled breath. Breast cancer research and treatment. 2011; 126:791-796.

80. Yu K, Wang Y, Yu J and Wang P. A Portable Electronic Nose Intended for Home Healthcare Based on a Mixed Sensor Array and Multiple Desorption Methods. Sensor Letters. 2011; 9:876-883.

81. Mazzone PJ, Wang XF, Xu Y, Mekhail T, Beukemann MC, Na J, Kemling JW, Suslick KS and Sasidhar M. Exhaled breath analysis with a colorimetric sensor array for the identification and characterization of lung cancer. Journal of thoracic oncology : official publication of the International Association for the Study of Lung Cancer. 2012; 7:137-142.

82. Santonico M, Lucantoni G, Pennazza G, Capuano R,
Galluccio G, Roscioni C, La Delfa G, Consoli D, Martinelli E, Paolesse R, Di Natale C and D'Amico A. In situ detection of lung cancer volatile fingerprints using bronchoscopic airsampling. Lung cancer (Amsterdam, Netherlands). 2012; 77:46-50.

83. Wang D, Yu K, Wang Y, Hu Y, Zhao C, Wang L, Ying K and Wang P. A Hybrid Electronic Noses' System Based on Mos-Saw Detection Units Intended for Lung Cancer Diagnosis. Journal of Innovative Optical Health Sciences. 2012; 5 .

84. Leunis N, Boumans ML, Kremer B, Din S, Stobberingh E, Kessels AG and Kross KW. Application of an electronic nose in the diagnosis of head and neck cancer. The Laryngoscope. 2014; 124:1377-1381.

85. McWilliams A, Beigi P, Srinidhi A, Lam S and MacAulay C. Sex and Smoking Status Effects on the Early Detection of Early Lung Cancer in High-Risk Smokers using an Electronic Nose. IEEE transactions on bio-medical engineering. 2015.

86. Shehada N, Bronstrup G, Funka K, Christiansen S, Leja $\mathrm{M}$ and Haick H. Ultrasensitive Silicon Nanowire for RealWorld Gas Sensing: Noninvasive Diagnosis of Cancer from Breath Volatolome. Nano letters. 2015; 15:1288-1295.

87. Gruber M, Tisch U, Jeries R, Amal H, Hakim M, Ronen O, Marshak T, Zimmerman D, Israel O, Amiga E, Doweck I and Haick H. Analysis of exhaled breath for diagnosing head and neck squamous cell carcinoma: a feasibility study. British journal of cancer. 2014; 111:790-798.

88. Amal H, Shi DY, Ionescu R, Zhang W, Hua QL, Pan YY, Tao L, Liu H and Haick H. Assessment of ovarian cancer conditions from exhaled breath. International journal of cancer Journal international du cancer. 2015; 136:E614622.

89. Phillips M, Gleeson K, Hughes JM, Greenberg J, Cataneo RN, Baker L and McVay WP. Volatile organic compounds in breath as markers of lung cancer: a cross-sectional study. Lancet. 1999; 353:1930-1933.

90. Peng G, Tisch U, Adams O, Hakim M, Shehada N, Broza YY, Billan S, Abdah-Bortnyak R, Kuten A and Haick H. Diagnosing lung cancer in exhaled breath using gold nanoparticles. Nature nanotechnology. 2009; 4:669-673.

91. Kischkel S, Miekisch W, Sawacki A, Straker EM, Trefz $\mathrm{P}$, Amann A and Schubert JK. Breath biomarkers for lung cancer detection and assessment of smoking related effects - confounding variables, influence of normalization and statistical algorithms. Clinica Chimica Acta. 2010; 411:1637-1644.

92. Patterson SG, Bayer CW, Hendry RJ, Sellers N, Lee KS, Vidakovic B, Mizaikoff B and Gabram-Mendola SG. Breath analysis by mass spectrometry: a new tool for breast cancer detection? The American surgeon. 2011; 77:747751.

93. Rudnicka J, Kowalkowski T, Ligor T and Buszewski B. Determination of volatile organic compounds as biomarkers 
of lung cancer by SPME-GC-TOF/MS and chemometrics. Journal of chromatography B, Analytical technologies in the biomedical and life sciences. 2011; 879:3360-3366.

94. Ulanowska A, Kowalkowski T, Trawinska E and Buszewski B. The application of statistical methods using VOCs to identify patients with lung cancer. Journal of breath research. 2011; 5:046008.

95. Mangler M, Freitag C, Lanowska M, Staeck O, Schneider A and Speiser D. Volatile organic compounds (VOCs) in exhaled breath of patients with breast cancer in a clinical setting. Ginekologia polska. 2012; 83:730-736.

96. Altomare DF, Di Lena M, Porcelli F, Trizio L, Travaglio E, Tutino M, Dragonieri S, Memeo V and de Gennaro G. Exhaled volatile organic compounds identify patients with colorectal cancer. The British journal of surgery. 2013; 100:144-150.

97. Garcia RA, Morales V, Martin S, Vilches E and Toledano A. Volatile Organic Compounds Analysis in Breath Air in Healthy Volunteers and Patients Suffering Epidermoid Laryngeal Carcinomas. Chromatographia. 2014; 77:501509.

98. Li J, Peng Y, Liu Y, Li W, Jin Y, Tang Z and Duan Y. Investigation of potential breath biomarkers for the early diagnosis of breast cancer using gas chromatography-mass spectrometry. Clinica chimica acta; international journal of clinical chemistry. 2014; 436:59-67.

99. Wang C, Sun B, Guo L, Wang X, Ke C, Liu S, Zhao W, Luo S, Guo Z, Zhang Y, Xu G and Li E. Volatile organic metabolites identify patients with breast cancer, cyclomastopathy, and mammary gland fibroma. Scientific reports. 2014; 4:5383.

100. Wang C, Ke C, Wang X, Chi C, Guo L, Luo S, Guo Z, Xu G, Zhang F and Li E. Noninvasive detection of colorectal cancer by analysis of exhaled breath. Analytical and bioanalytical chemistry. 2014; 406:4757-4763.

101. Guo L, Wang C, Chi C, Wang X, Liu S, Zhao W, Ke C, $\mathrm{Xu} \mathrm{G}$ and $\mathrm{Li}$ E. Exhaled breath volatile biomarker analysis for thyroid cancer. Translational research : the journal of laboratory and clinical medicine. 2015.

102. Hietanen E, Bartsch H, Bereziat JC, Camus AM, McClinton $\mathrm{S}$, Eremin O, Davidson L and Boyle P. Diet and oxidative stress in breast, colon and prostate cancer patients: a casecontrol study. European journal of clinical nutrition. 1994; 48:575-586.

103. Rieder J, Lirk P, Ebenbichler C, Gruber G, Prazeller P, Lindinger W and Amann A. Analysis of volatile organic compounds: possible applications in metabolic disorders and cancer screening. Wiener klinische Wochenschrift. 2001; 113:181-185.

104. Steeghs MM, Cristescu SM, Munnik P, Zanen P and Harren FJ. An off-line breath sampling and analysis method suitable for large screening studies. Physiological measurement. 2007; 28:503-514.

105. Handa H, Usuba A, Maddula S, Baumbach JI, Mineshita M and Miyazawa T. Exhaled breath analysis for lung cancer detection using ion mobility spectrometry. PloS one. 2014; 9:e114555.

106. Ma H, Li X, Chen J, Wang H, Cheng T, Chen K and Xu S. Analysis of human breath samples of lung cancer patients and healthy controls with solid-phase microextraction (SPME) and flow-modulated comprehensive twodimensional gas chromatography (GC x GC). Analytical Methods. 2014; 6:6841-6849.

107. Kumar S, Huang J, Abbassi-Ghadi N, Mackenzie HA, Veselkov KA, Hoare JM, Lovat LB, Spanel P, Smith D and Hanna GB. Mass Spectrometric Analysis of Exhaled Breath for the Identification of Volatile Organic Compound Biomarkers in Esophageal and Gastric Adenocarcinoma. Annals of surgery. 2015.

108. Phillips M. Method for the collection and assay of volatile organic compounds in breath. Analytical biochemistry. 1997; 247:272-278. 